\title{
Missed opportunity
}

The analysis by Rosenthal et al. of the profession's response to Bill 16 in Ontario should be required reading in pharmacy curricula across the country. After all, students should know something about the culture of their chosen profession. For all the talk of moving forward, of expanded services and a new model of practice, it is all just that: talk. The majority of pharmacists do not have the confidence or the commitment to embrace the role of "carers of patients." When faced with a crisis that threatens the bottom line, but with an opportunity to reshape the raison d'être of the profession, many pharmacists instead clung helplessly to the past, to that safety blanket we call dispensing.

Perhaps it is fear of the unknown that pushes pharmacists and pharmacy organizations to so steadfastly embrace the status quo. Perhaps it is a misplaced sense of security. Many in the profession love to point to the fact that year after year, pharmacists rank near or at the top of the Ipsos Reid poll of most trusted profession (see page 55). Would we stand so tall in the public's eyes, I wonder, if they ever realized that the most trusted profession is more concerned with "pharmacist," "pharmacy" and "professional allowances" than it is with "patient care"? Public perception can change quickly; our profession apparently cannot.

- Thuan Nguyen, BScPhm

Toronto, ON

\section{Reference}

1. Rosenthal M, Austin Z, Tsuyuki RT. Ontario pharmacists' crisis over Bill 16: a missed opportunity? Can Pharm J 2012;145:35-9. 